\title{
The use of sulfide cluster-derived catalysts to understand the promotional effect in hydrotreatment catalysis
}

\author{
J R Brenner, B T Carvill* and L T Thompson, Jrt
}

Department of Chemical Engineering, University of Michigan, 3026 H.H. Dow Bldg, 2300 Hayward Avenue, Ann Arbor, Michigan 48109-2136, USA

Sulfide cluster-derived ensembles are promising models of the active sites in commercial hydrotreatment catalysts. A series of sulfide clusters were adsorbed intact onto high-surface-area $\gamma$ alumina, magnesium oxide and activated carbon supports, then pretreated to produce highly dispersed catalytic ensembles with sizes similar to those of their precursor clusters. The activities of the bimetallic cluster-derived catalysts were significantly higher than those of the monometallic catalysts. We took this as evidence that direct interactions between molybdenum and the promoter element cause the promotional effect observed in commercial hydrotreatment catalysts. The hydrodesulfurization and hydrodenitrogenation activities correlated with the extent of molybdenum reduction. Our results suggested that the active sites in promoted hydrotreatment catalysts are centered on molecular-scale ensembles containing molybdenum, sulfur and the promoter element.

Keywords: Hydrotreatment, hydrodesulfurization, hydrodenitrogenation, molybdenum, clusters, thiophene, pyridine

\section{INTRODUCTION}

The promotional effect of late transition metals on early transition metal sulfide hydrotreatment catalysts has been extensively investigated. Most commercial hydrotreatment consist of molybdenum or tungsten sulfides promoted with cobalt or nickel. Models proposed to explain the promotional effects in hydrodesulfurization catalysis can be grouped according to the importance of the interaction between molybdenum (or tungsten) and the promoter element, $M$ (cobalt, nickel or iron). The monolayer and contact synergy models

*Current address: Chemical Engineering Department, Northwestern University, Evanston, IL 60208, USA.

$\dagger$ Author to whom correspondence should be addressed. are characterized by weak or indirect interactions between molybdenum and $M$. In contrast, the intercalation and 'CoMoS' models are characterized by strong, direct interactions between the promoter and molybdenum. Most of our understanding of the active sites in hydrodenitrogenation (HDN) catalysis is drawn from analogies with hydrodesulfurization (HDS) catalysis.

The monolayer model describes the active site as a vacancy in a one-dimensional molybdenum chain bound to the support. ${ }^{1-4}$ It is believed that the promoter element helps stabilize the molybdenum chain thus increasing the number of vacancies. Delmon ${ }^{5}$ proposed that the active sites for HDS are $\mathrm{Mo}^{3+}$ ions located at the interface of $\mathrm{MoS}_{2}$ and $\mathrm{Co}_{9} \mathrm{~S}_{8}$ phases. He explained the promotional effect of cobalt on both supported and unsupported molybdenum disulfide catalysts in terms of a 'contact synergy' model. It was proposed that the bulk promoter provides sites for hydrogen activation while the molybdenum sulfide sites utilize this hydrogen to activate $\mathrm{C}-\mathrm{S}$ bonds. Inherent in this model is the spillover of hydrogen from the donor (bulk promoter sulfide) to the acceptor (bulk molybdenum sulfide). No evidence for hydrogen spillover has yet been observed however.

The intercalation model claims that promoter atoms intercalate between layers of $\mathrm{MoS}_{2}$ crystallites. ${ }^{6}$ The primary function of the promoter in this model is to reduce the molybdenum oxidation state. A model with many similarities to, but wider acceptance than, the intercalation model is the 'CoMoS' model proposed by Topsøe and coworkers. ${ }^{7.8}$ This model was based on a linear relationship between the HDS activity and the amount of cobalt giving rise to a distinct Mössbauer emission spectrum. Based on X-ray absorption spectroscopy results, Topsøe and co-workers ${ }^{9}$ suggested that cobalt cations pseudointercalate at edge sites of single $\mathrm{S}-\mathrm{Mo}-\mathrm{S}$ slabs, the building blocks of bulk $\mathrm{MoS}_{2}$. 


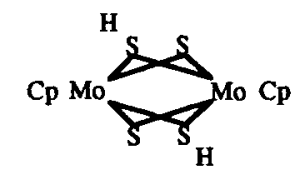

MoS

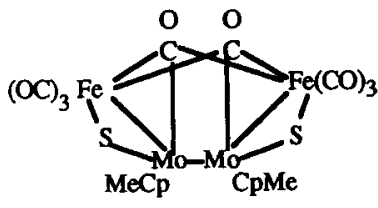

MoFeS

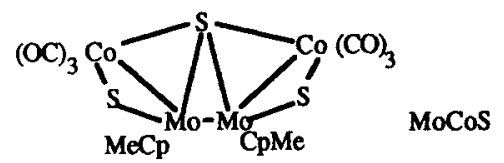

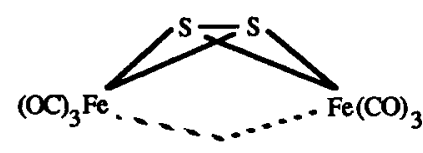

FeS

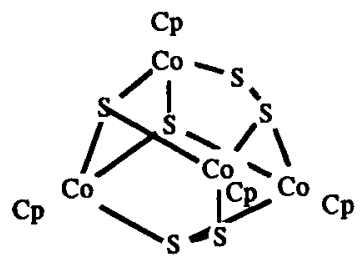

$\operatorname{CoS}$

Figure 1 Schematic illustration of the organometallic sulfide cluster precursors used to prepare the heterogeneous catalysts.

Despite extensive study there still is no single model that accounts for the features of all promoted hydrotreatment catalysts. In this research we used heterogeneous sulfide cluster-derived catalysts to understand better the character of the active sites in hydrotreatment catalysts. Clusters tend to produce uniform molecular ensembles that are more amenable to characterization than conventionally-prepared catalytic phases. Furthermore, these 'solid-state metal complex' catalysts can be used to elucidate fundamental information concerning reaction mechanisms. ${ }^{10-12}$ The sulfide cluster-derived catalysts were useful in evaluating the importance of the interactions between molybdenum, sulfur and the promoter element in hydrotreatment catalysis. In addition, the need for bulk phases was assessed.

\section{EXPERIMENTAL}

\section{Synthesis}

The molybdenum-containing clusters $\mathrm{Cp}_{2} \mathrm{Mo}_{2}(\mu-\mathrm{SH})_{2}(\mu-\mathrm{S})_{2}$ [abbreviated to $\mathrm{MoS}$ ], $(\mathrm{MeCp})_{2} \mathrm{Mo}_{2} \mathrm{Fe}_{2}\left(\mu_{3}-\mathrm{S}\right)_{2}(\mathrm{CO})_{8} \quad[\mathrm{MoFeS}], \quad$ and $(\mathrm{MeCp})_{2} \mathrm{Mo}_{2} \mathrm{Co}_{2}\left(\mu_{4}-\mathrm{S}\right)_{2}(\mathrm{CO})_{4}[\mathrm{MoCoS}]$, where $\mathrm{Cp}=$ cyclopentadienyl and $\mathrm{MeCp}=$ methylcyclopentadienyl, were synthesized according to procedures described by Rakowski DuBois et al. ${ }^{13}$ and Curtis and co-workers. ${ }^{14,15}$ Catalysts were also prepared from $\mathrm{Fe}(\mu-\mathrm{S})_{2}(\mathrm{CO})_{6}$ [FeS] and $\mathrm{Cp}_{4} \mathrm{Co}_{4}\left(\mu_{3}-\mathrm{S}\right)_{2}\left(\mu_{3}-\mathrm{S}_{2}\right)_{2}$ [CoS] precursors. ${ }^{16,17}$ Figure 1 illustrates the clusters that were employed in this research.
These clusters were dispersed onto highsurface-area supports by the equilibrium adsorption method so as to produce a $1 \mathrm{wt} \%$ metal loading. The $\gamma-\mathrm{Al}_{2} \mathrm{O}_{3}$ (Catapal, $150 \mathrm{~m}^{2} \mathrm{~g}^{-1}$ ) and magnesium oxide ( $\mathrm{MgO}$; Alfa, $80 \mathrm{~m}^{2} \mathrm{~g}^{-1}$ ) were calcined at $773 \mathrm{~K}$ in dry air for $5 \mathrm{~h}$, while the activated carbon (Alfa, $1100 \mathrm{~m}^{2} \mathrm{~g}^{-1}$ ) was prereduced in hydrogen at $673 \mathrm{~K}$ for $12 \mathrm{~h}$ prior to use. For future reference, $\mathrm{A}, \mathrm{M}$ and $\mathrm{C}$ refer to $\gamma-\mathrm{Al}_{2} \mathrm{O}_{3}, \mathrm{MgO}$ and activated carbon, respectively. A solution of the desired sulfide cluster dissolved in distilled $\mathrm{CH}_{2} \mathrm{Cl}_{2}$ was added to a slurry of the support in distilled $\mathrm{CH}_{2} \mathrm{Cl}_{2}$. The resulting solution was vigorously stirred under nitrogen for an hour before the solvent was evaporated off under vacuum. The dried catalysts were stored under nitrogen for further use. Some of the clusterderived catalysts used in this work are known to be air-sensitive ${ }^{18}$ even though the neat clusters retain their structural integrity over extended periods of time in air. Thus care was taken to minimize or eliminate air exposure. Unsupported $\mathrm{MoS}_{2}$ (Alfa) and Katalco 477, a commercial cobalt-molybdate catalyst $(2-5 \mathrm{wt} \% \mathrm{CoO}, 12-$ 16 wt $\% \mathrm{MoO}_{3}$, and the balance $\gamma-\mathrm{Al}_{2} \mathrm{O}_{3}$ ) were also examined. The Katalco catalyst was received in the form of pellets and was ground to a coarse powder prior to use.

\section{Fourier transform infrared spectroscopy (FTIR)}

Neat and supported clusters were physically mixed with dry $\mathrm{KBr}$ so as to give a nominal ratio of $1 \mathrm{mg}$ cluster per $\mathrm{g}$ total and then pressed into a $0.25 \mathrm{in}(6.3 \mathrm{~mm})$ diameter pellet inside a 
nitrogen-filled polyethylene glove bag. The pellet was then taken out of the glove bag and exposed to ambient conditions for no more than $2 \mathrm{~min}$ prior to being placed into the nitrogen-purged sample chamber of the spectrometer (Nicolet $510 \mathrm{P}$ ). For samples that were heated in situ, selfsupporting wafers were used. Spectra (1000 scans) were recorded over the range of $4000-400 \mathrm{~cm}^{-1}$ using a DTGS detector at $4 \mathrm{~cm}^{-1}$ resolution. Peak positions were determined by taking derivatives of the spectra.

\section{High-resolution transmission electron microscopy (HRTEM)}

A few grains $(\sim 0.01 \mathrm{~g})$ of the cluster-derived catalysts were ground in isopropanol using an agate mortar and pestle inside a nitrogen-purged polyethylene glove bag. The resulting slurry was sealed under nitrogen into a flask and sonicated for $30 \mathrm{~min}$ before placing the flask back into the glove bag. A drop of the slurried cluster was dispersed onto a holey carbon grid and allowed to dry for an hour under nitrogen. The grid was loaded into the TEM sample holder and transported to the microscope so that air exposure was limited to about $1 \mathrm{~min}$. Grids containing the blank supports were prepared without taking measures to eliminate air exposure.

High-resolution TEM was accomplished using a JEOL $4000 \mathrm{EX}$, which has a point-to-point resolution of $1.7 \AA(0.17 \mathrm{~nm})$ and line-to-line resolution of $1.4 \AA$. We restricted our view to regions overhanging holes in the copper grid with preference for regions near the edge of the support because of contrast considerations. All photographs were taken at a magnification of 500000 . Crystalline regions of the support provided useful cross-referencing distances. Digitization and Fourier transformation of the images was accomplished using MacImage/FFT. ${ }^{19}$

\section{Sorption analysis}

Oxygen chemisorption was used to estimate the site density. Both oxygen ${ }^{20-22}$ and nitric oxide $(\mathrm{NO})^{23.24}$ have been used in attempts to titrate active sites in hydrotreatment catalysts. We could not use NO with our instrument because of potential corrosion problems. Tauster et al ${ }^{25}$ observed a nearly linear relationship between the HDS activity and oxygen uptake of unpromoted transition metal sulfides. While there is some controversy about whether this type of correlation exists for promoted molybdenum and tungsten sulfides, oxygen uptake provides a rough estimate of the site density. Because oxygen can dissolve into the sulfide lattice, we used the dynamic pulsedadsorption technique at low temperatures. Oxygen uptake experiments were carried out using a Quantasorb sorption analyzer. The pretreatment protocol consisted of purging the catalyst bed with helium, followed by reduction in hydrogen at $673 \mathrm{~K}$ for at least $4 \mathrm{~h}$. The catalyst was purged with helium before cooling to room temperature. The Katalco catalyst was presulfided in the flow reactor. The sorption experiments consisted of submerging the sample loop containing the catalyst into a dry ice-acetone bath $(195 \mathrm{~K})$ followed by the adsorption of $9.98 \%$ oxygen-helium until the eluted peak area was constant for at least three consecutive injections. This ensured that the surface was saturated.

\section{Catalyst testing}

Approximately $0.2 \mathrm{~g}$ of the catalyst was loaded into a Pyrex flow reactor over a plug of glass wool. Typically the exposure to air was less than $10 \mathrm{~min}$. A thermocouple was placed directly into the catalyst bed, and the catalyst temperature was held to within $\pm 1 \mathrm{~K}$ of the set point. Prepurified helium and hydrogen were further purified during passage through a commercial combination oxygen-and-moisture trap (Matheson). The catalysts were pyrolyzed by heating in helium at $2 \mathrm{~K} \mathrm{~min}^{-1}$ up to $673 \mathrm{~K}$. The temperature was held at $673 \mathrm{~K}$ for an hour and then lowered to $573 \mathrm{~K}$. Finally, the catalyst was reduced in hydrogen at $573 \mathrm{~K}$ for half an hour before increasing the temperature to $673 \mathrm{~K}$ at $2 \mathrm{~K} \mathrm{~min}^{-1}$. Immediately prior to the activity measurement, the catalyst was reduced in hydrogen overnight at $673 \mathrm{~K}$. The $\mathrm{MoS}_{2}$ and Katalco catalysts were sulfided for $4 \mathrm{~h}$ in a $2 \% \mathrm{H}_{2} \mathrm{~S}$-hydrogen mixture at $673 \mathrm{~K}$ and then reduced overnight at the same temperature prior to use.

Reactants and products were separated using a 1.8-m Hayesep D column (Alltech) and analyzed using a Hewlett-Packard 5890 gas chromatograph. Peak areas and retention times were determined using a SpectraPhysics integrator and calibrated using standard alkane and alkene gas mixtures (Scott, $\pm 2 \%$ ). Activities were measured under differential conditions (conversion $<5 \%$ ) at $573-648 \mathrm{~K}$ and atmospheric pressure using a reactant mixture containing either $2.7 \%$ thiophene (Aldrich, $99+\%$ ) or $0.6 \%$ pyridine 
(Aldrich, 99+\%) in hydrogen. Reaction rates were normalized, based on the cluster loading or oxygen uptake. No change in activity was observed when the flow rate was varied between 10 and $40 \mathrm{sccm}$, confirming the absence of external mass transport limitations.

\section{X-ray photoelectron spectroscopy (XPS)}

$\mathrm{X}$-ray photoelectron spectroscopy was performed on pressed wafers ( $\sim 100 \mathrm{mg}$ of catalyst) using a PHI Model 5400 ESCA spectrometer. The vacuum in the test chamber was typically less than $3 \times 10^{-9}$ torr during the measurement. Spectra were collected after in situ reduction in hydrogen and/or sulfiding in a $2 \%$ hydrogen- $\mathrm{H}_{2} \mathrm{~S}$ mixture at $673 \mathrm{~K}$, using the $\mathrm{Al} \mathrm{K}$ source. Charging effects were accounted for using the $\mathrm{Al}(2 p)$ peak at $74.8 \mathrm{eV}$. Details concerning the deconvolution procedure have been published elsewhere. ${ }^{26}$ Errors in the binding energies and peak areas were estimated to be $\pm 0.3 \mathrm{eV}$ and $\pm 10 \%$, respectively.

\section{Mössbauer spectroscopy}

The Mössbauer experiments were carried out in a specially designed in situ cell. For the pure cluster spectra, $\sim 150 \mathrm{mg}$ of sample was pressed into a small wafer and loaded into the cell. Special samples of the MoFeS/A catalyst were prepared using MoFeS that had been enriched with $35 \%$ ${ }^{57} \mathrm{Fe}$. Approximately $400 \mathrm{mg}$ of catalyst was pressed into a $\frac{3}{4}$-in diameter $(19 \mathrm{~mm})$ wafer and loaded into the cell. Mössbauer spectra could be collected at temperatures up to $740 \mathrm{~K}$. After pyrolysis in helium at $673 \mathrm{~K}$ for $24 \mathrm{~h}$, the catalyst was cooled to $\sim 573 \mathrm{~K}$ in helium, then reduced in flowing hydrogen. Reduction in hydrogen at $673 \mathrm{~K}$ preceded the in situ HDS experiments which were performed at $\sim 101 \mathrm{kPa}$ using a flowing mixture of $2.7 \%$ thiophene in hydrogen.

\section{RESULTS}

\section{Fourier transform infrared spectroscopy}

In all cases the infrared spectra of the supported clusters were similar to those of the pure clusters. This suggested that the clusters were adsorbed onto the support intact. Figure 2 compares the infrared spectrum for the pure MoCoS cluster with those of the virgin $\mathrm{Al}_{2} \mathrm{O}_{3}, \mathrm{MgO}$ and activated carbon-supported MoCoS clusters. The two strong peaks in the terminal carbonyl stretch region were essentially invariant in comparing the various supports. The most significant shifts were observed for the $\mathrm{MgO}$-supported MoCoS. Subtle shifts were also observed for the $\mathrm{Al}_{2} \mathrm{O}_{3}$-supported $\mathrm{MoFeS}$ cluster. Both the terminal and bridging $\mathrm{CO}$ ligand stretches were shifted by $4-10 \mathrm{~cm}^{-1}$ to higher frequency, indicating a slight oxidation of the iron on contact of the cluster with $\mathrm{Al}_{2} \mathrm{O}_{3}$. There were also modest variations in features in the $\mathrm{C}-\mathrm{H}$ stretch region (Fig. 3).

Upon heating, the carbonyl band positions remained constant for both the MoCoS and MoFeS clusters up to the point of abrupt and complete loss of IR activity at $\sim 380 \mathrm{~K}$. No new bands were observed at higher temperatures and $\mathrm{CO}$ could not be readsorbed onto either catalyst. The narrow desorption temperature ranges observed for these samples suggested that the surfaces were fairly uniform and that the clusters may have been molecularly dispersed. These results were consistent with temperatureprogrammed decomposition results which indicated that the $\mathrm{CO}$ and $\mathrm{Cp}$ ligands were removed at approximately $380 \mathrm{~K}$ and $480 \mathrm{~K}$, respectively. ${ }^{27}$ Residual amounts of carbon were present in the thermally treated samples, while essentially all of the sulfur was retained. ${ }^{27}$

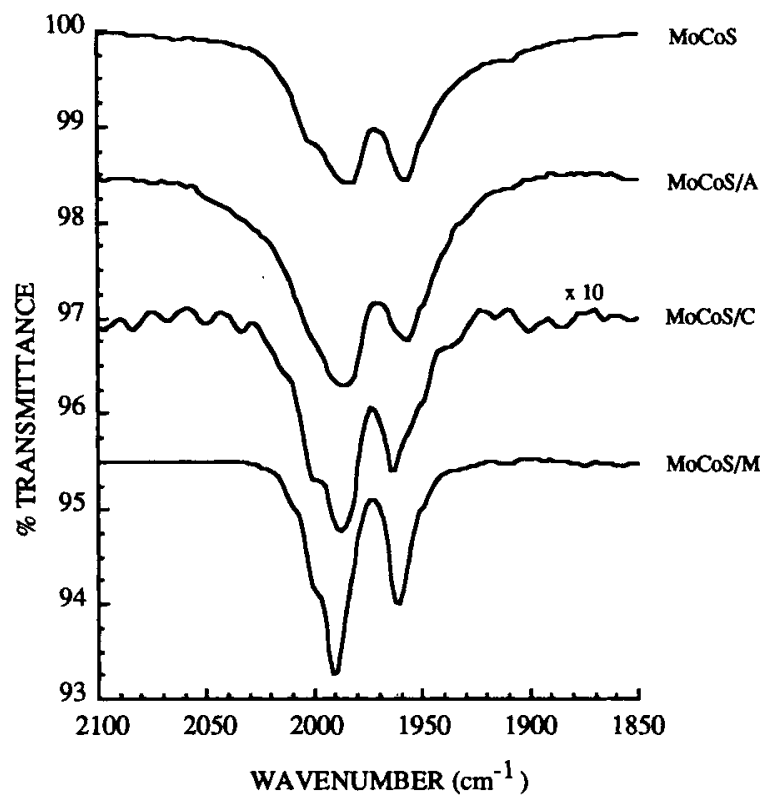

Figure 2 Infrared spectra of the carbonyl stretch region of the neat and supported MoCoS cluster. The spectra suggested that the interactions of this cluster with the supports were relatively weak. 


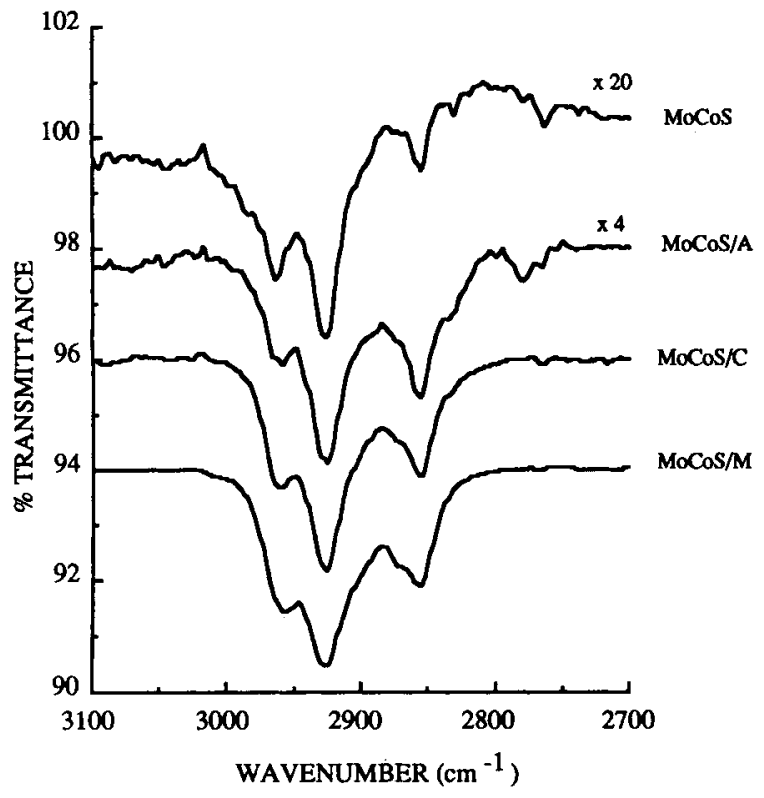

Figure 3 Infrared spectra of the $\mathrm{C}-\mathrm{H}$ stretch region of the neat and supported MoCoS cluster. Although the peak positions were essentially invariant with respect to the supports, the relative intensities varied.

\section{High-resolution transmission electron microscopy}

The MoFeS/A, MoCoS/M, MoCoS/A and MoCoS/C catalysts were extensively examined using high-resolution transmission electron microscopy. There was no evidence of any particles larger than $10 \AA$ other than the support particles in any of the samples. These results are consistent with X-ray diffraction results which revealed only the structure of the support. Figure 4 is an exemplary micrograph from a section of the $\mathrm{MoFeS} / \mathrm{A}$ catalyst. The absence of features clearly attributable to the clusters implied that the clusters were molecularly dispersed or disintegrated to produce atomic sites.

Some small scattering centers (see arrows) superimposed on lattice fringes attributed to the $\{400\}$ and $\{222\}$ planes of MgO $\left(a_{0}=8.12 \AA\right.$; Ref. 28) can be seen in Fig. 5. The sizes of these features are nominally $10 \AA$, which is consistent with the size of a single MoCoS cluster. The largest distinguishable scattering centers in the thermally treated samples were $\sim 4 \AA$. We expected that the energy supplied by the electron beam would be sufficient to remove the carbonyl and cyclopentadienyl ligands, ${ }^{27,29}$ thereby reducing the diameter of the clusters from roughly $10 \AA$ to about $4 \AA$. As a precaution, we attempted to keep the electron beam current low enough to prevent this transformation from taking place. We cannot yet conclusively say that the metalsulfur framework remained intact on the surface. Scattering centers of $\sim 4 \AA$ were also observed in the MoCoS/A and MoFeS/A catalysts; however, no such features were distinguishable for the $\mathrm{MoCoS} / \mathrm{C}$ catalyst.

The small scattering centers observed in the $\mathrm{MoCoS} / \mathrm{M}, \mathrm{MoCoS} / \mathrm{A}$ and MoFeS/A catalysts were not observed in the untreated blank supports (Fig. 6). After wetting the blank supports with $\mathrm{CH}_{2} \mathrm{Cl}_{2}$ and drying them under vacuum, an amorphous film of up to $1 \mathrm{~nm}$ thickness was observed around the edges of all the supports including the activated carbon. The origin of this film is unknown at this point; however, there were no features similar to those attributed to the cluster-derived ensembles.

\section{Catalytic behavior}

In this work we used oxygen chemisorption to estimate the site densities. The use of oxygen chemisorption for $\mathrm{MoS}_{2}$ has been well received. ${ }^{20,21}$ The similarity between the cluster loading and the oxygen uptake suggested that oxygen chemisorption would also be useful for normalizing the activities of the cluster-derived catalysts (Table 1). Furthermore, the results suggested that the cluster-derived ensembles were highly, perhaps molecularly, dispersed.

The thiophene HDS and pyridine HDN activities typically reached steady state after $\sim 30 \mathrm{~min}$ on stream. The activities and product distributions could be maintained for more than $24 \mathrm{~h}$ on stream with little or no detectable deactivation. Furthermore, the catalytic properties were reproducible through at least several reaction/ reduction cycles. Each cluster produced a unique catalyst, an indication that the cluster constituents did not agglomerate into particles.

\section{Thiophene HDS}

Exemplary Arrhenius plots of the steady-state HDS activities are illustrated in Fig. 7. The reaction rates and turnover frequencies are compared in Table 2. The activity of the MoCoS/A catalyst was the highest among the cluster-derived catalysts and was similar to that of the $\mathrm{Co}-\mathrm{Mo} / \gamma-\mathrm{Al}_{2} \mathrm{O}_{3}$ (Katalco) catalyst. In addition, the activity of $\mathrm{MoS} / \mathrm{A}$ was similar to that of $\mathrm{MoS}_{2}$. As mentioned earlier, there is some concern with the use 


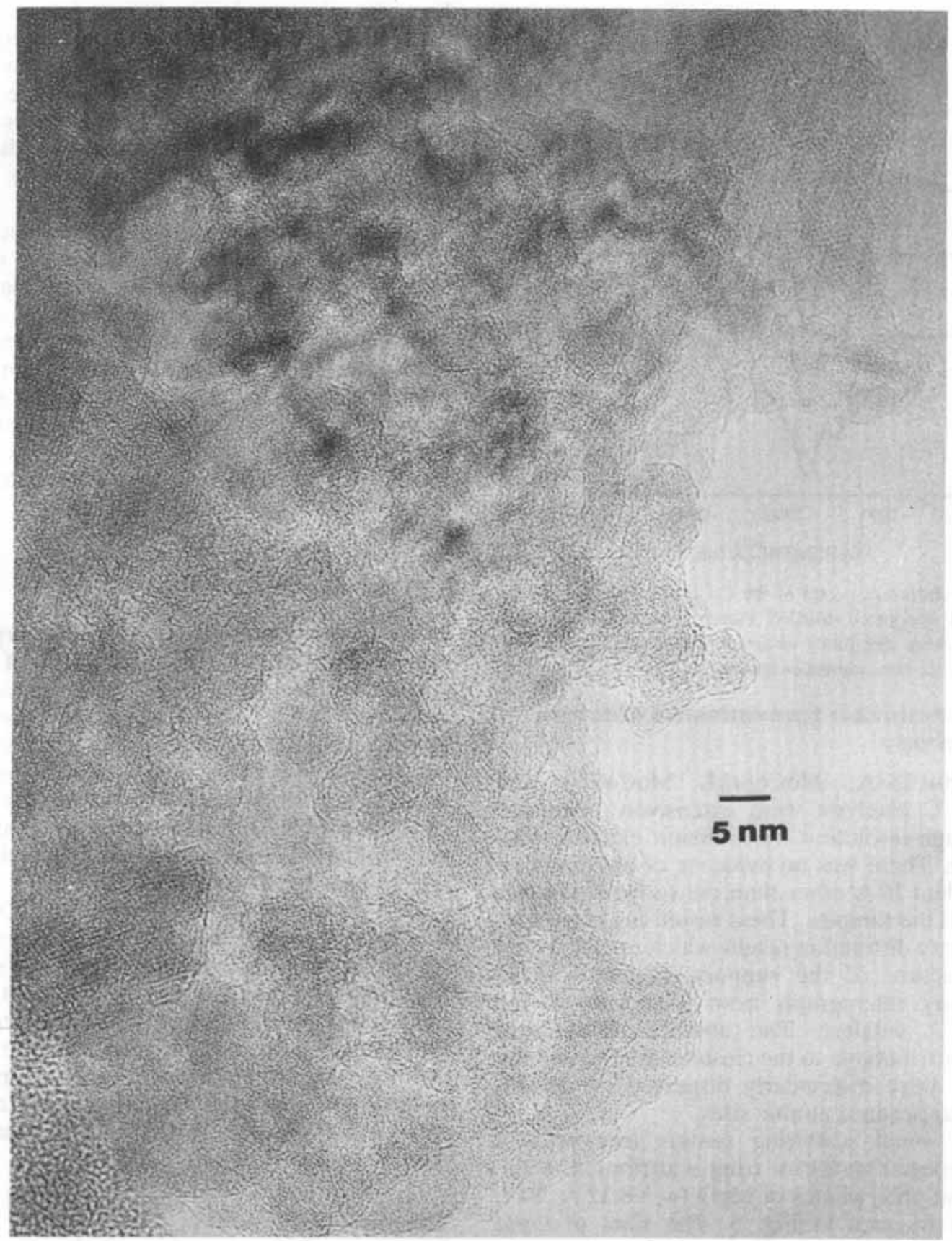

Figure 4 High-resolution transmission electron micrograph of the MoFeS/A catalyst. There is no evidence of domains larger than $10 \AA$ other than those of the $\gamma-\mathrm{Al}_{2} \mathrm{O}_{3}$ support.

of oxygen chemisorption for titrating active sites in promoted hydrotreatment catalysts. It has been reported that oxygen chemisorbs on both promoted and unpromoted sites $;{ }^{20-22}$ thus, the oxygen uptake based activity should be viewed as an average activity for the $\mathrm{CoMo} / \gamma-\mathrm{Al}_{2} \mathrm{O}_{3}$ catalyst and a lower limit of the intrinsic activity of promoted sites in this catalyst. Nevertheless, normalizing activities by oxygen uptake seemed appropriate for 'order of magnitude' comparisons between the cluster-derived ensembles and the conventionally prepared catalysts. 


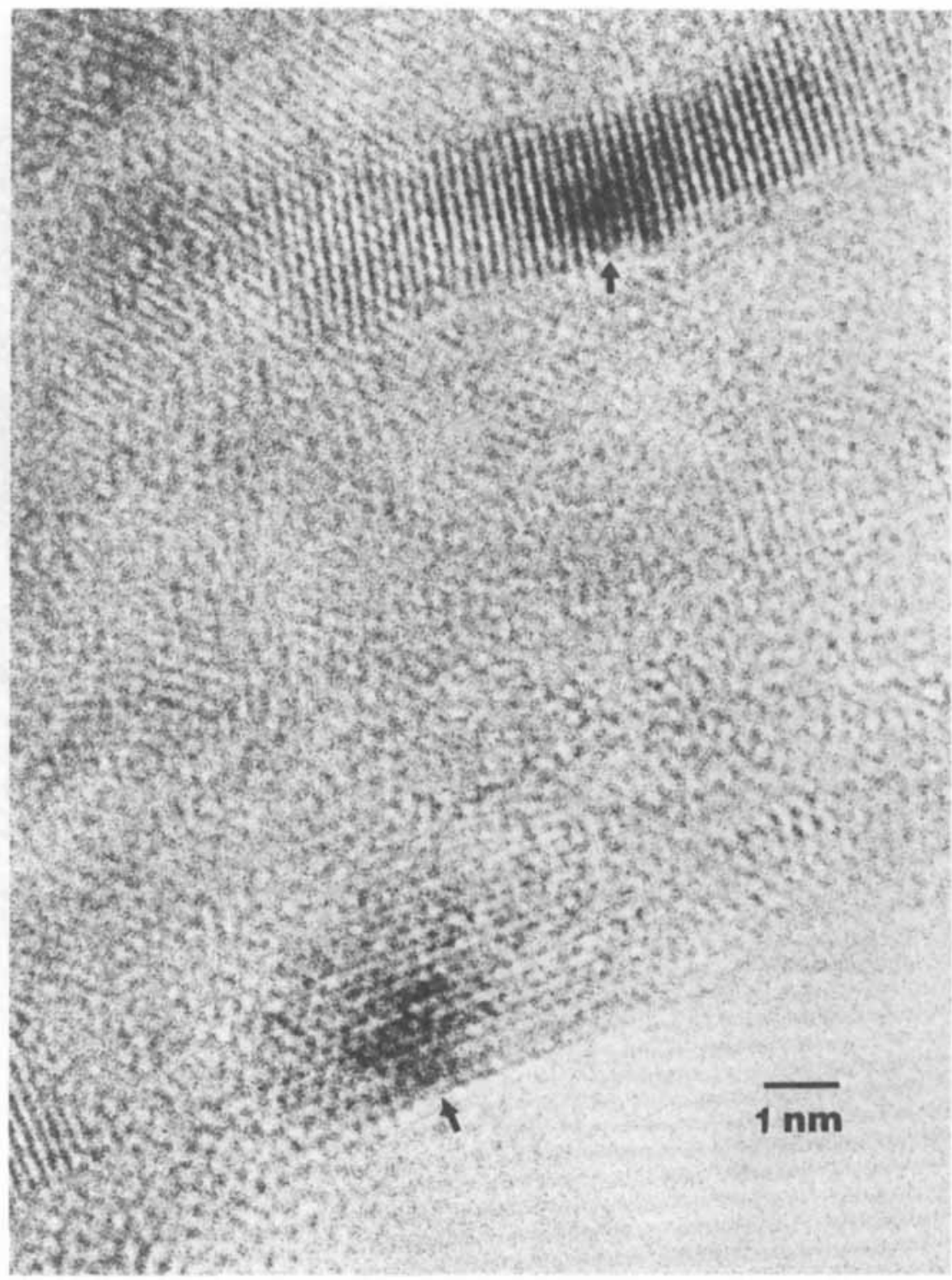

Figure 5 High-resolution electron micrograph of MoCoS/M. Superimposed on the lattice fringes from the $\{400\}$ and $\{222\}$ planes of $\mathrm{MgO}$ are regions of dark contrast on the order of $\sim 10 \AA$ which we attributed to the MoCoS clusters.

The activities descended in the following order for the $\mathrm{Al}_{2} \mathrm{O}_{3}$ series; $\mathrm{MoCoS} / \mathrm{A}>\mathrm{CoMo} / \gamma-$ $\mathrm{Al}_{2} \mathrm{O}_{3}>\mathrm{MoFeS} / \mathrm{A}>\mathrm{MoS}_{2}>\mathrm{MoS} / \mathrm{A}>\mathrm{MoS} /$ $\mathrm{CoS} / \mathrm{A}>\mathrm{MoS} / \mathrm{FeS} / \mathrm{A}>\mathrm{CoS} / \mathrm{A} \simeq \mathrm{FeS} / \mathrm{A}$. This pattern is consistent with the order of activities reported for conventionally prepared metal sulfide catalysts. ${ }^{30-32}$ Note that the activities of the $\mathrm{MoS} / \mathrm{CoS}-$ and MoS/FeS-derived catalysts were intermediate to those of the MoS-, CoS- and FeS-derived catalysts. This implies that the clusters did not interact. Apparent activation energies for thiophene consumption ranged from 10 to 23 $\mathrm{kcal} \mathrm{mol}^{-1}$ (42 to $97 \mathrm{~kJ} \mathrm{~mol}^{-1}$ ). These values were similar to those reported for other HDS catalysts. ${ }^{30-32}$ In addition, the $\mathrm{C}_{4}$ and $\mathrm{C}_{3}$ hydrocarbon apparent activation energies were similar, suggesting similar reaction mechanisms.

The primary products for thiophene HDS over most of the sulfide cluster-derived catalysts were butenes and propene (Fig. 8). Small amounts of ethylene and ethane were also produced. The sulfided $\mathrm{Co}-\mathrm{Mo} / \gamma-\mathrm{Al}_{2} \mathrm{O}_{3}$ catalyst produced butenes in distributions similar to those observed for the cluster-derived catalysts. In addition, the 


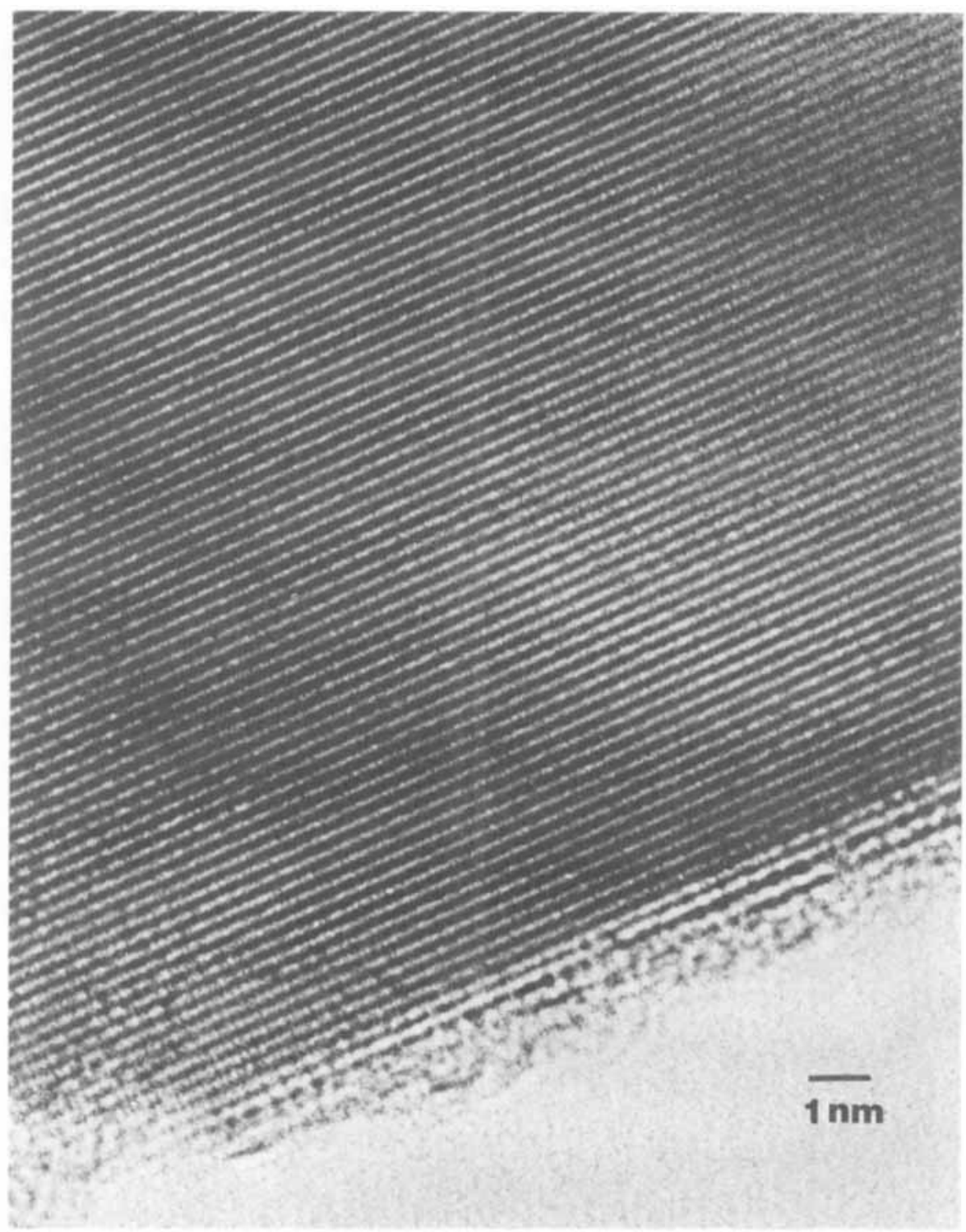

Figure 6 An edge-on view of the $\mathrm{MgO}$ support which had been wetted with $\mathrm{CH}_{2} \mathrm{Cl}_{2}$ under nitrogen and dried under vacuum. An amorphous film of $\sim 1 \mathrm{~nm}$ thickness is observed on the surface. Notice that the MgO retains a high degree of crystallinity.

$\mathrm{Co}-\mathrm{Mo} / \gamma-\mathrm{Al}_{2} \mathrm{O}_{3}$ catalyst produced significant amounts of butane. The similar activities and selectivities of the cluster-derived and conventionally prepared catalysts led us to conclude that the sulfide cluster-derived ensembles were reasonable models of the sites in both unpromoted and promoted HDS catalysts; MoCoS/A for $\mathrm{Co}-\mathrm{Mo} / \gamma-\mathrm{Al}_{2} \mathrm{O}_{3}$ and $\mathrm{MoS} / \mathrm{A}$ for $\mathrm{MoS}_{2}$ and $\mathrm{MoS}_{2} / \mathrm{Al}_{2} \mathrm{O}_{3}$.

The activities of the $\mathrm{MgO}$-supported catalysts in most cases were significantly lower than their $\mathrm{Al}_{2} \mathrm{O}_{3}$-supported counterparts with the possible exception of the FeS- and MoCoS-derived catalysts (Table 2). This result suggests that the character of the support affected the active site. One might expect the support to have a stronger influence on the cluster-derived catalysts than on conventionally-prepared catalysts due to the high dispersion of the cluster-derived ensembles.

An interaction between the MoS and CoS clusters is implied by the very high activity observed for $\mathrm{MoS} / \mathrm{CoS} / \mathrm{M}$. The low loadings employed in this research were selected specifically to limit interactions of the clusters. The origin of this 
Table 1 Cluster loading and chemisorption properties The abbreviations $\mathrm{A}, \mathrm{M}$ and $\mathrm{C}$ refer to $\gamma-\mathrm{Al}_{2} \mathrm{O}_{3}, \mathrm{MgO}$ and activated carbon, respectively.

\begin{tabular}{|c|c|c|c|c|c|}
\hline \multirow{2}{*}{$\begin{array}{l}\text { Catalyst } \\
\text { code }\end{array}$} & \multicolumn{2}{|c|}{$\begin{array}{l}\text { Loading } \\
\text { (wt } \% \text { ) }\end{array}$} & \multirow{2}{*}{$\begin{array}{l}\begin{array}{l}\text { Cluster } \\
(\mu \mathrm{mol})\end{array} \\
\mathrm{g}_{\mathrm{cat}}\end{array}$} & \multirow{2}{*}{$\frac{\mathrm{O}_{2}^{\mathrm{b}}(\mu \mathrm{mol})}{\mathrm{g}_{\mathrm{cat}}}$} & \multirow{2}{*}{$\begin{array}{l}\text { Chusters } \\
\mathrm{O}_{2}\end{array}$} \\
\hline & Mo & $\mathbf{M}^{\mathrm{a}}$ & & & \\
\hline $\mathrm{MoS} / \mathrm{A}$ & 1.01 & 0.00 & 52.1 & 14.5 & 3.6 \\
\hline $\mathrm{CoS} / \mathrm{A}$ & 0.00 & 1.00 & 42.2 & 19.2 & 2.2 \\
\hline $\mathrm{FeS} / \mathrm{A}$ & 0.00 & 1.00 & 89.1 & 15.1 & 5.9 \\
\hline $\operatorname{MoS} / \operatorname{CoS} / \mathrm{A}$ & 0.62 & 0.38 & 48.4 & 9.6 & 5.1 \\
\hline MoS/FeS/A & 0.63 & 0.37 & 65.9 & 14.5 & 4.5 \\
\hline $\operatorname{MoCoS} / \mathrm{A}$ & 0.62 & 0.38 & 32.3 & 7.5 & 4.3 \\
\hline $\mathrm{MoFeS} / \mathrm{A}$ & 0.63 & 0.37 & 32.9 & 6.5 & 5.1 \\
\hline MoS/M & 1.00 & 0.00 & 52.8 & 12.0 & 4.4 \\
\hline $\operatorname{CoS} / \mathrm{M}$ & 1.00 & 0.00 & 42.9 & 11.3 & 3.8 \\
\hline $\mathrm{FeS} / \mathrm{M}$ & 1.00 & 0.00 & 89.1 & 25.5 & 3.5 \\
\hline $\mathrm{MoS} / \mathrm{CoS} / \mathrm{M}$ & 0.62 & 0.38 & 48.4 & 17.7 & 2.7 \\
\hline $\mathrm{MoS} / \mathrm{FeS} / \mathrm{M}$ & 0.63 & 0.37 & 65.9 & 14.7 & 4.5 \\
\hline $\mathrm{MoCoS} / \mathrm{M}$ & 0.62 & 0.38 & 32.3 & 21.3 & 1.5 \\
\hline $\mathrm{MoCoS} / \mathrm{C}$ & 0.62 & 0.38 & 32.3 & 23.3 & 1.4 \\
\hline $\mathrm{MoS}_{2}$ & - & 一 & - & 10.4 & - \\
\hline $\mathrm{Co}-\mathrm{Mo} / \gamma-\mathrm{Al}_{2} \mathrm{O}_{3}$ & $8-11$ & $1-4$ & - & 108.1 & - \\
\hline
\end{tabular}

${ }^{a}$ Promoter element (iron or cobalt). ${ }^{\mathrm{b}}$ Pulsed chemisorption at $195 \mathrm{~K}$.

apparent interaction is as yet unknown; nevertheless, the MoS/CoS/M catalyst was more than an order of magnitude more active than any of the other $\mathrm{MgO}$-series catalysts.

\section{Pyridine HDN}

The pyridine HDN activities of the clusterderived catalysts were about two orders of magnitude lower than the thiophene HDS activities (Table 3). Qualitatively similar differences have been reported for conventionally prepared catalysts. ${ }^{33,34}$ The order of the activities for HDN over the $\mathrm{Al}_{2} \mathrm{O}_{3}$-supported catalysts was similar to that observed for $\mathrm{HDS}$ : $\mathrm{MoCoS} / \mathrm{A}>$ $\mathrm{MoS} / \mathrm{CoS} / \mathrm{A} \simeq \mathrm{MoS} / \mathrm{FeS} / \mathrm{A}>\mathrm{Co}-\mathrm{Mo} / \gamma-\mathrm{Al}_{2} \mathrm{O}_{3}>$ $\mathrm{MoFeS} / \mathrm{A}>\mathrm{CoS} / \mathrm{A}>\mathrm{FeS} / \mathrm{A} \simeq \mathrm{MoS} / \mathrm{A}$. Catalytic ensembles derived from the bimetallic clusters were in general more active than their monometallic cluster-derived counter parts (Fig. 9). MoCoS/A was the most active of all the $\mathrm{Al}_{2} \mathrm{O}_{3}$-supported catalysts. The activity of the sulfided $\mathrm{Co}-\mathrm{Mo} / \gamma-\mathrm{Al}_{2} \mathrm{O}_{3}$ catalyst was significantly lower than that of MoCoS/A, however, it was similar to the activity of MoFeS/A. This difference may be due to the inadequacy of oxygen to titrate only the promoted active sites or to differences in the intrinsic properties of active sites in the cluster-derived and conventionally prepared catalysts. It is also possible that differences in the dispersions of the sites were responsible for the dissimilar activities. We note that no dispersion effects were observed for thiophene HDS over these same catalysts. $^{26}$

Among the monometallic catalysts, $\mathrm{CoS} / \mathrm{A}$ was the most active, although the activities of all the monometallic catalysts were quite low. Catalysts derived from two monometallic cluster precursors displayed higher HDN activities than any of the monometallic catalysts. This suggested that the clusters interacted.

The activation energies for HDN over the cluster-derived catalysts paralleled those of conventionally prepared catalysts. Despite their different activities, the activation energies for the $\mathrm{MoCoS} / \mathrm{A}$ and $\mathrm{Co}-\mathrm{Mo} / \gamma-\mathrm{Al}_{2} \mathrm{O}_{3}$ catalysts were similar.

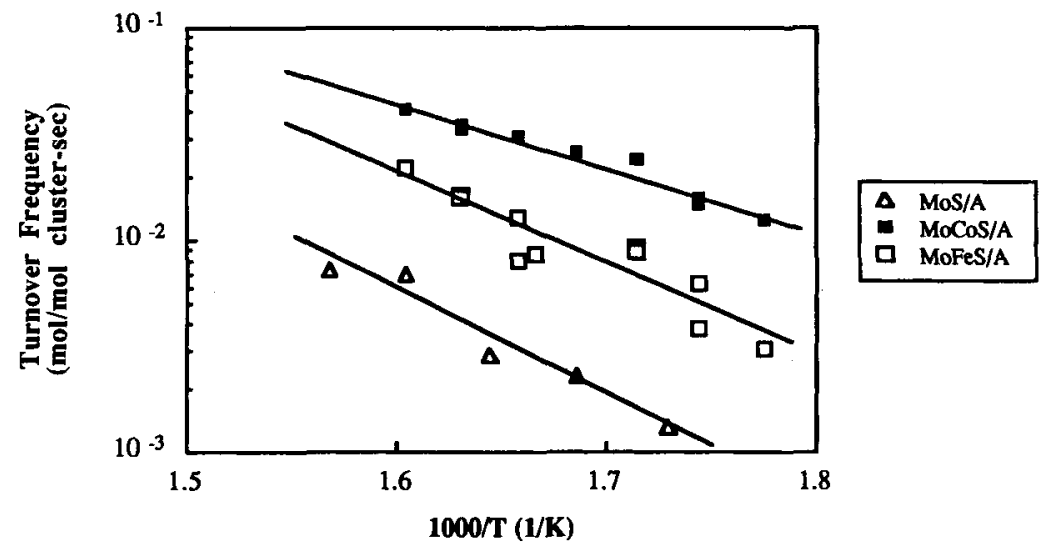

Figure 7 Thiophene HDS activities of some of the cluster-derived catalysts. Activities of the bimetallic cluster-derived catalysts exceeded those of the monometallic catalysts, suggesting a promotional effect. This general trend in activities is in agreement with that for conventionally prepared catalysts. 
Table 2 Thiophene hydrodesulfurization reaction rates and activities

Note the similarities between the activities and activation energies of the MoCoS/A and $\mathrm{Co}-\mathrm{Mo} / \gamma-\mathrm{Al}_{2} \mathrm{O}_{3}$ catalysts.

\begin{tabular}{|c|c|c|c|c|}
\hline \multirow{2}{*}{$\begin{array}{l}\text { Catalyst } \\
\text { code }\end{array}$} & \multirow{2}{*}{$\begin{array}{l}\text { Reaction rate } \\
\left(\text { nmol } g_{c a t}{ }^{-1} s^{-1}\right)\end{array}$} & \multicolumn{2}{|c|}{ Turnover frequency $\left(\times 10^{5}\right)$} & \multirow{2}{*}{$\begin{array}{l}\Delta E_{\mathrm{a}} \\
\left(\mathrm{kcal} \mathrm{mol}^{-1}\right)^{\mathrm{c}}\end{array}$} \\
\hline & & (mol/mol cluster per s) & $\left(\mathrm{mol} / \mathrm{mol} \mathrm{O} \mathrm{O}_{2}\right.$ per s) & \\
\hline $\mathrm{MoS} / \mathrm{A}$ & 28 & 53.4 & 194.4 & 22.3 \\
\hline $\operatorname{CoS} / \mathrm{A}$ & 1 & 3.2 & 7.0 & $\sim^{b}$ \\
\hline $\mathrm{FeS} / \mathrm{A}$ & 1 & 1.0 & 6.2 & $-{ }^{b}$ \\
\hline $\operatorname{MoS} / \operatorname{CoS} / \mathrm{A}$ & 7 & 13.6 & 69.0 & 14.3 \\
\hline $\mathrm{MoS} / \mathrm{FeS} / \mathrm{A}$ & 37 & 3.9 & 17.6 & 10.7 \\
\hline $\mathrm{MoFeS} / \mathrm{A}$ & 28 & 85.0 & 431.2 & 19.2 \\
\hline $\mathrm{MoCoS} / \mathrm{A}$ & 72 & 229.3 & 964.1 & 13.8 \\
\hline $\mathrm{MoS} / \mathrm{M}$ & 3 & 5.4 & 23.6 & $-\mathrm{b}$ \\
\hline $\operatorname{CoS} / \mathrm{M}$ & 2 & 4.4 & 16.5 & 8.8 \\
\hline $\mathrm{FeS} / \mathrm{M}$ & 1 & 0.9 & 3.1 & 19.5 \\
\hline $\mathrm{MoS} / \mathrm{CoS} / \mathrm{M}$ & 59 & 122.0 & 333.8 & 9.7 \\
\hline $\mathrm{MoS} / \mathrm{FeS} / \mathrm{M}$ & 1 & 2.1 & 9.5 & $-^{b}$ \\
\hline $\mathrm{MoS}_{2}$ & 29 & - & 277.7 & 17.6 \\
\hline $\mathrm{Co}-\mathrm{Mo} / \gamma-\mathrm{Al}_{2} \mathrm{O}_{3}$ & 831 & - & 769.2 & 13.5 \\
\hline
\end{tabular}

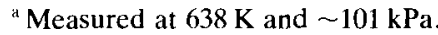

${ }^{\mathrm{h}}$ Activity too low to measure. ${ }^{c} 1 \mathrm{kcal} \mathrm{mol}^{-1} \simeq 4.2 \mathrm{~kJ} \mathrm{~mol}^{-1}$.

The $\mathrm{MgO}$-series catalysts were less active than the $\mathrm{Al}_{2} \mathrm{O}_{3}$ series catalysts, implying support effects for HDN catalysis. A comparison of the activities of the MoCoS/C, MoCoS/A and MoCoS/M provided further evidence of support effects. The MoCoS/C catalyst was twice as active as either of the oxide-supported catalysts. Activated carbon has been reported to be a more effective support for hydrotreatment catalysts than $\mathrm{Al}_{2} \mathrm{O}_{3}$ or $\mathrm{MgO}{ }^{35}$ De Beer and co-workers ${ }^{36,37}$ have shown that the activity of sulfided $\mathrm{Co}-\mathrm{Mo} / \gamma-\mathrm{Al}_{2} \mathrm{O}_{3}$ approached that of their carbon-supported analogs only after the
$\mathrm{Al}_{2} \mathrm{O}_{3}$-supported materials were sulfided at high temperatures (873-973 K). Presumably the high temperatures permitted the metals to be more thoroughly sulfided. For the cluster-derived catalysts the metal/sulfur ratios (as determined by XPS) were essentially the same for the carbonand oxide-supported catalysts; thus, we cannot attribute differences in the activities to differences in the degrees of sulfiding. Carbon is thought of as an inert support; hence, we believe the results indicate that a weak interaction between the support and the clusters gave rise to the most active HDN catalysts.

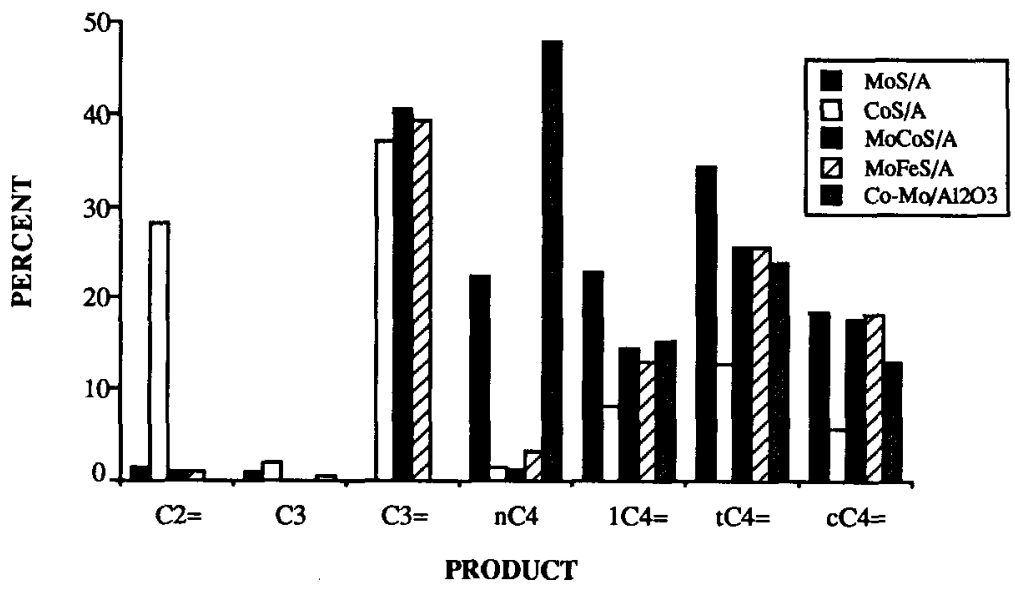

Figure 8 Thiophene HDS product distributions over the cluster-derived catalysts and a commercial $\mathrm{Co}-\mathrm{Mo} / \gamma-\mathrm{Al}_{2} \mathrm{O}_{3}$ catalyst. 
Table 3 Pyridine HDN reaction rates and activities

Carbon appears to be a more effective support for the clusters than the oxide supports.

\begin{tabular}{|c|c|c|c|c|}
\hline \multirow{2}{*}{$\begin{array}{l}\text { Catalyst } \\
\text { code }\end{array}$} & \multirow{2}{*}{$\begin{array}{l}\text { Reaction rate } \\
\left(\mathrm{pmol} \mathrm{g}_{\mathrm{cat}}^{-1} \mathrm{~s}^{-1}\right)\end{array}$} & \multicolumn{2}{|c|}{ Turnover frequency $\left(\times 10^{7}\right)$} & \multirow{2}{*}{$\begin{array}{l}\Delta E_{\mathrm{a}} \\
\left(\mathrm{kcal} \mathrm{mol}^{-1}\right)^{\mathrm{b}}\end{array}$} \\
\hline & & (mol/mol cluster per s) & $(\mathrm{mol} / \mathrm{mol} \mathrm{O}$ per s) & \\
\hline MoS/A & 18 & 3.4 & 12.2 & 22.4 \\
\hline $\operatorname{CoS} / \mathrm{A}$ & 51 & 12.2 & 26.8 & 16.2 \\
\hline $\mathrm{FeS} / \mathrm{A}$ & 20 & 2.2 & 12.7 & 34.4 \\
\hline $\operatorname{MoS} / \operatorname{CoS} / \mathrm{A}$ & 107 & 22.0 & 119.2 & 15.8 \\
\hline $\mathrm{MoS} / \mathrm{FeS} / \mathrm{A}$ & 175 & 26.6 & 120.9 & 22.2 \\
\hline $\mathrm{MoFeS} / \mathrm{A}$ & 33 & 10.1 & 51.5 & 19.2 \\
\hline $\mathrm{MoCoS} / \mathrm{A}$ & 172 & 53.3 & 229.2 & 20.0 \\
\hline $\mathrm{MoS} / \mathrm{M}$ & 5 & 0.9 & 4.0 & 16.5 \\
\hline $\mathrm{CoS} / \mathrm{M}$ & 2 & 0.4 & 1.5 & 21.9 \\
\hline $\mathrm{FeS} / \mathrm{M}$ & 40 & 4.4 & 15.4 & 34.2 \\
\hline $\mathrm{MoS} / \mathrm{CoS} / \mathrm{M}$ & 5 & 1.1 & 3.0 & 19.2 \\
\hline $\mathrm{MoS} / \mathrm{FeS} / \mathrm{M}$ & 11 & 1.6 & 7.2 & 20.2 \\
\hline $\mathrm{MoCoS} / \mathrm{M}$ & 525 & 161.8 & 245.3 & 17.2 \\
\hline $\mathrm{MoCoS} / \mathrm{C}$ & 1055 & 325.0 & 450.5 & 12.8 \\
\hline $\mathrm{Co}-\mathrm{Mo} / \gamma-\mathrm{Al}_{2} \mathrm{O}_{3}$ & 7530 & - & 69.7 & 19.0 \\
\hline
\end{tabular}

${ }^{a}$ Measured at $633 \mathrm{~K}$ and $\sim 101 \mathrm{kPa} .{ }^{b} 1 \mathrm{kcal} \mathrm{mol}^{-1} \simeq 4.2 \mathrm{~kJ} \mathrm{~mol}^{-1}$.

In general, the product distribution varied with the character of the cluster. The monometallic cluster-derived catalysts, in particular the FeSand CoS-derived catalysts, produced mostly methane. The MoS-derived catlaysts also produced similar amounts of propylene. The MoCoS-derived catalysts were generally more selective to $\mathrm{C}_{4}$ hydrocarbons, with the distribution among the $\mathrm{C}_{4}$ hydrocarbons varying with support. The MoCoS/M series produced mostly butenes while the $\mathrm{Al}_{2} \mathrm{O}_{3}$ - and carbon-supported clusters produced more butane. Kolousek et al. reported that $\mathrm{MgO}$-supported catalysts are very selective for $\mathrm{C}-\mathrm{S}$ bond activation over $\mathrm{C}=\mathrm{C}$ bond hydrogenation, but their activities were low compared with $\mathrm{Al}_{2} \mathrm{O}_{3}$-supported catalysts. ${ }^{33}$ The $\mathrm{MoCoS} / \mathrm{C}$ catalyst was the only one to produce $\mathrm{C}_{5}$ hydrocarbons (Fig. 10). Product distributions for the sulfided $\mathrm{Co}-\mathrm{Mo} / \gamma-\mathrm{Al}_{2} \mathrm{O}_{3}$ catalyst were significantly different from those of the cluster-derived catalysts. The MoFeS/A catalyst was unique among the cluster-derived catalysts in producing almost

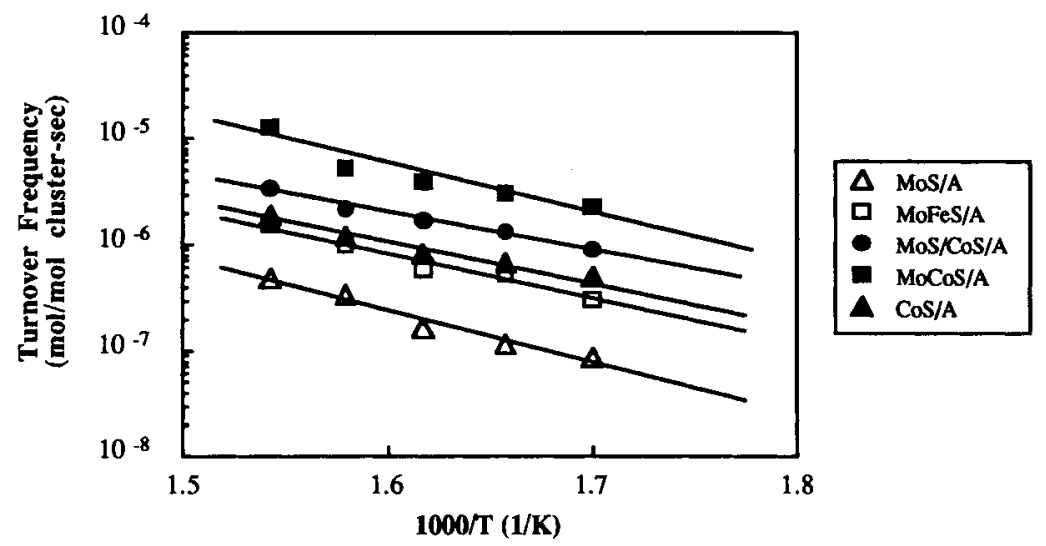

Figure 9 Pyridine $\mathrm{HDN}$ activities of the $\mathrm{Al}_{2} \mathrm{O}_{3}$-series catalysts. The most active catalyst was that derived from the MoCoS cluster, for which the interaction between molybdenum and the promoter element is expected to be strong and direct. 


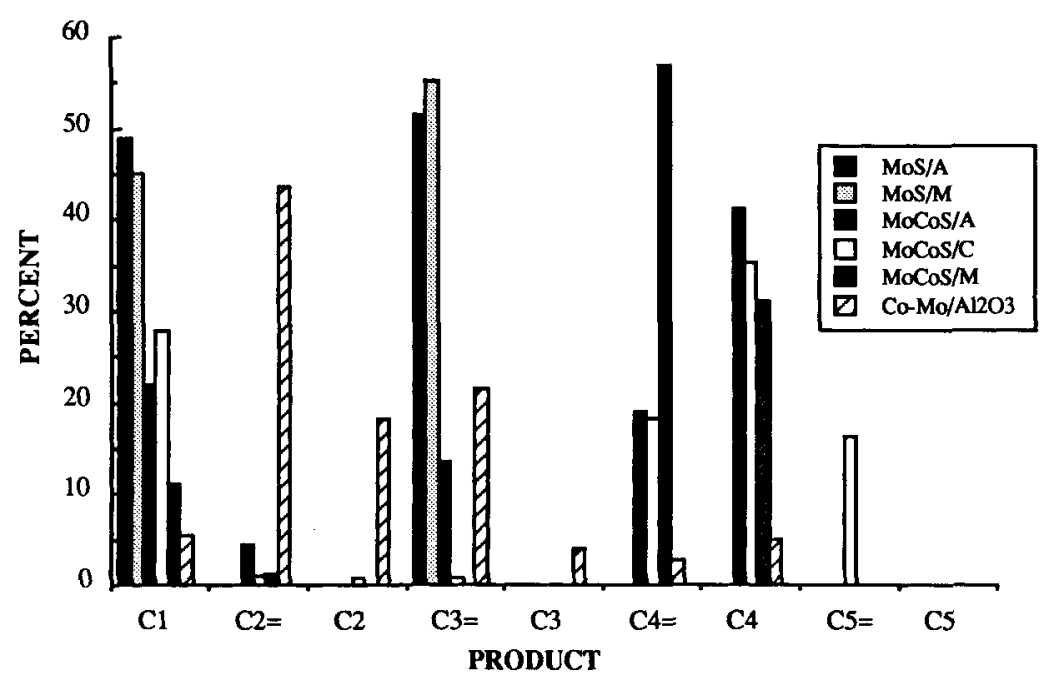

Figure 10 A comparison of the pyridine HDN product distributions of the MoS- and MoCoS-derived catalysts with that of the $\mathrm{Co}-\mathrm{Mo} / \gamma-\mathrm{Al}_{2} \mathrm{O}_{3}$ catalyst.

equal proportions of $\mathrm{C}_{2}$ and $\mathrm{C}_{3} \mathrm{~s}$. The sulfided $\mathrm{Co}-\mathrm{Mo} / \gamma-\mathrm{Al}_{2} \mathrm{O}_{3}$ catalyst produced more than $80 \%$ $\mathrm{C}_{2}$ and $\mathrm{C}_{3}$ hydrocarbons.

To summarize, the catalytic properties for pyridine HDN were somewhat different from those for thiophene HDS. While the product distributions for HDS over the cluster-derived catalysts were similar, the HDN product distributions varied with the character of the precursor cluster. In addition, the order of the activities of the monometallic clusters were reversed for HDN compared with that for HDS. These results suggest that the HDN sites in commercial hydrotreatment catalysts are somewhat different from the HDS sites. While there is some support for this claim, ${ }^{2-4}$ the predominance of evidence reported in the literature suggests that HDS and HDN occur on similar or identical sites.

\section{$X$-ray photoelectron spectroscopy}

The oxidation states of molybdenum in the pure clusters were generally consistent with the formal oxidation states determined on the basis of theoretical arguments. From electron-counting arguments, the states of molybdenum and iron in MoFeS are $3+$ and 0 , respectively. ${ }^{15}$ The oxidation state for molybdenum determined using XPS was consistent with the formal oxidation state. The sum of charges on the molybdenum and cobalt atoms in MoCoS is +8 . The $\mu_{4}$-S ligand demands a delocalized description of the bonding in this electron-deficient cluster; ${ }^{15}$ thus formal oxidation states cannot be assigned. The XPS spectrum suggested the presence of $\mathrm{Mo}^{2+}$. The average oxidation state of molybdenum in the MoS cluster was slightly less than $2+$, in contrast to the formal oxidation-state assignment of $4+$.

$\mathrm{X}$-ray photoelectron spectra of the clusterderived catalysts were collected after in situ reduction in hydrogen at $673 \mathrm{~K}$ and following sulfiding in a mixture of $2 \% \mathrm{H}_{2} \mathrm{~S}$ in hydrogen at $673 \mathrm{~K}$. The sulfiding step was included to determine whether sulfur could be incorporated or removed from the catalysts. Furthermore, $\mathrm{H}_{2} \mathrm{~S}$ is produced during thiophene HDS; thus, its presence partially simulates the conditions prevailing during catalysis. No difference between the spectra of the reduced and sulfided cluster-derived ensembles was observed, indicating that there was no sulfur incorportion into or removal from the cluster-derived ensembles. Recall that presulfiding did not affect the activities of the clusterderived catalysts.

Deconvolution of the spectra suggested the presence of a species with binding energy of $\sim 228 \mathrm{eV}$. This species has been attributed to $\mathrm{Mo}^{\delta+}$ where $0<\delta<4$. The MoS- and MoCoS-derived catalysts contained large amounts of reduced molybdenum, and it appeared that cobalt may enhance the reducibility of molybdenum (Table 4). The average state of molybdenum reduction as estimated from the relative peak areas and oxidation states (assuming $\delta=2$ ) decreased as follows: $\mathrm{MoCoS} / \mathrm{A}>$ $\mathrm{MoS} / \mathrm{A}>\mathrm{Co}-\mathrm{Mo} / \gamma-\mathrm{Al}_{2} \mathrm{O}_{3}>\mathrm{MoFeS} / \mathrm{A}>\mathrm{MoS}_{2} .{ }^{24}$ With the exception of MoS/A, this order agreed 
Table 4 The distribution of molybdenum states as determined by $\mathrm{X}$-ray photoelectron spectroscopy. The extent of reduction tracked with both the HDS and HDN activities.

\begin{tabular}{|c|c|c|c|c|c|c|}
\hline \multirow{2}{*}{$\begin{array}{l}\text { Catalyst } \\
\text { code }\end{array}$} & \multicolumn{4}{|c|}{ Mo $3 d_{5 / 2}$ binding energies ${ }^{\mathrm{a}}(\mathrm{eV})$} & \multicolumn{2}{|c|}{ Normalized TOF } \\
\hline & $\mathrm{Mo}^{0}$ & $\mathrm{Mo}^{\delta+}$ & $\mathrm{Mo}^{4+}$ & $\mathrm{Mo}^{6+}$ & HDS & HDN \\
\hline MoS/A & $227.8(44)^{\mathrm{c}}$ & $228.8(36)$ & $230.1(6)$ & $232.9(13)$ & 20 & 5 \\
\hline MoFeS/A & $227.8(2)$ & $228.8(77)$ & $230.2(10)$ & $232.5(11)$ & 45 & 22 \\
\hline $\mathrm{MoCoS} / \mathrm{A}$ & $227.9(62)$ & $228.9(21)$ & $230.3(8)$ & $232.9(9)$ & 100 & 100 \\
\hline $\mathrm{MoS}_{2}$ & $227.7(3)$ & $228.7(18)$ & $229.8(79)$ & - & 29 & - \\
\hline $\mathrm{Co}-\mathrm{Mo} / \gamma-\mathrm{Al}_{2} \mathrm{O}_{3}$ & $227.5(9)$ & $228.7(73)$ & $230.2(10)$ & $232.9(9)$ & 80 & 30 \\
\hline
\end{tabular}

${ }^{a}$ Following reduction in hydrogen at $673 \mathrm{~K}$ and sulfiding in $2 \% \mathrm{H}_{2} \mathrm{~S} / \mathrm{H}_{2}$ at $673 \mathrm{~K}$. ${ }^{\mathrm{b}}$ Area percentage is shown in parentheses. ${ }^{\mathrm{C}}$ Normalized upon oxygen uptake basis.

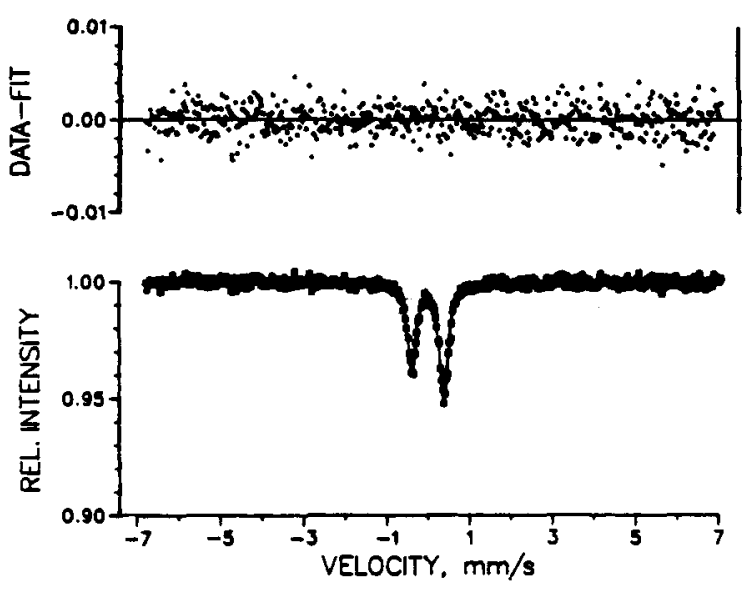

Figure 11 Mössbauer spectrum of the pure MoFeS cluster in air at room temperature. The spectral parameters are consistent with the presence of $\mathrm{Fe}^{0}$, which is in agreement with the formal oxidation state from electron-counting arguments.

with that for both the HDS and HDN activities. Despite the relatively high degree of reduction, MoS/A was among the lowest-activity catalysts. This implies that the molybdenum oxidation state is not the only determinant for the HDS or HDN activities and the catalytic ensembles are centered on more than just the molybdenum. Finally, the local S/Mo and M/Mo atomic ratios as determined by XPS were similar to those for the cluster precursors, which is evidence that, with the exception of the removal of the IR-active ligands, the composition of the clusters remained essentially constant during reducing and sulfiding conditions.

\section{Mössbauer spectroscopy}

Figure 11 shows the Mössbauer spectrum of the pure $\mathrm{MoFeS}$ cluster at room temperature. Note the asymmetry of the peaks. An asymmetric doublet would result from either preferential orientation of the material due to compacting, or the Goldanskii-Karyagin effect. ${ }^{38}$ The Goldanskii-Karyagin effect is caused by an anisotropic recoil-free fraction and has been confirmed in only a few compounds. ${ }^{39}$ In polycrystalline materials it is very difficult to differentiate between the Goldanskii-Karyagin and texturing effects. Although the sample was randomized by regrinding, the spectra did not change significantly. Thus we concluded that the doublet was inherently asymmetric. The pure MoFeS had an isomer shift of $+0.01 \mathrm{~mm} \mathrm{~s}^{-1}$ and a quadrupole splitting of $0.78 \mathrm{~mm} \mathrm{~s}^{-1}$. The isomer shift was in accordance with either $\mathrm{Fe}^{0}$, low-spin $\mathrm{Fe}^{2+}$ or lowspin $\mathrm{Fe}^{3+}$. Based on a 62-electron count, the formal oxidation state of iron in the cluster would be zero. ${ }^{14}$ The spectrum did not vary with temperature, so we ruled out $\mathrm{Fe}^{3+}$ and attributed the doublet to $\mathrm{Fe}^{0}$.

The in situ Mössbauer spectroscopic results are summarized in Table 5. The isomer shift and quadrupole splitting for the virgin MoFeS/A catalyst were $0.350 \mathrm{~mm} \mathrm{~s}^{-1}$ and $0.980 \mathrm{~mm} \mathrm{~s}^{-1}$, respectively (Fig. 12). The isomer shift suggested the presence of $\mathrm{Fe}^{3+}$. Evidently the iron in the cluster was oxidized during contact with the $\gamma-\mathrm{Al}_{2} \mathrm{O}_{3}$ and/or exposure to air at room temperature. It is also possible that heat generated during sample preparation (pressing) caused the oxidation. The spectral parameters were similar to those of the FeMoS phase ${ }^{8}$ an analog of the CoMoS phase that Topsøe and co-workers proposed as the active species for HDS catalysis.

Pretreatment in hydrogen at $673 \mathrm{~K}$ caused primarily the reduction of $\mathrm{Fe}^{3+}$ to $\mathrm{Fe}^{2+}$. Small quantities of an additional species, $\mathrm{Fe}^{\xi+}$, were also detected in the reduced catalyst. This $\mathrm{Fe}^{\xi+}$ species appeared to be more reduced than $\mathrm{Fe}^{2+}$ - thus the 
Table 5 In situ Mössbauer spectroscopic parameters for MoFeS/A

Pretreatment in hydrogen at $673 \mathrm{~K}$ caused a reduction of $\mathrm{Fe}^{3+}$ to $\mathrm{Fe}^{2+}$ and sulfiding caused little further change in the iron.

\begin{tabular}{|c|c|c|c|c|c|c|c|c|c|}
\hline \multirow[b]{2}{*}{ Exposure } & \multicolumn{3}{|l|}{$\mathrm{Fe}^{3+}$} & \multicolumn{3}{|l|}{$\mathrm{Fe}^{2+}$} & \multicolumn{3}{|l|}{$\mathrm{Fe}^{\xi+}$} \\
\hline & $\begin{array}{l}\text { IS } \\
\left(\mathrm{mm} \mathrm{s}^{-1}\right)\end{array}$ & 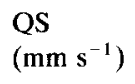 & Area $(\%)$ & $\begin{array}{l}\text { IS } \\
\left(\mathrm{mm} \mathrm{s}^{-1}\right)\end{array}$ & $\begin{array}{l}\mathrm{QS} \\
\left(\mathrm{mm} \mathrm{s}^{-1}\right)\end{array}$ & Area $(\%)$ & $\begin{array}{l}\text { IS } \\
\left(\mathrm{mm} \mathrm{s}^{-1}\right)\end{array}$ & $\begin{array}{l}\mathrm{QS} \\
\left(\mathrm{mm} \mathrm{s}^{-1}\right)\end{array}$ & Area $(\%)$ \\
\hline Fresh & 0.35 & 0.98 & 100 & & & & & & \\
\hline $673 \mathrm{~K}$ Hydrogen & & & & 1.02 & 1.90 & 91 & 0.08 & 0.43 & 9 \\
\hline $593 \mathrm{~K}$ Hydrogen-thio. ${ }^{\mathrm{a}}$ & & & & 1.02 & 2.02 & 86 & 0.14 & 0.60 & 14 \\
\hline $\mathrm{RT}^{\mathrm{b}} / \mathrm{Air}$ & 0.34 & 1.12 & 73 & 1.08 & 2.15 & 27 & & & \\
\hline
\end{tabular}

${ }^{a}$ Reactant mixture containing $1.5 \%$ thiophene in hydrogen. ${ }^{b}$ Room temperature.

assignment $\mathrm{Fe}^{\xi+}$ where $\xi<2$. It is possible but not likely that this species if $\mathrm{Fe}^{+}$(there are very few known $\mathrm{Fe}^{+}$species). Figure 13 illustrates the effect of exposure of $\mathrm{MoFeS} / \mathrm{A}$ to a mixture of thiophene $(1.5 \%)$ in hydrogen. The spectra were nearly identical, indicating that the chemical state of iron in the MoFeS/A catalyst was not significantly altered. Furthermore, extended periods of time on stream did not change the spectra. Exposure of the reduced MoFeS/A catalyst to air at room temperature resulted in the oxidation of $\mathrm{Fe}^{2+}$ in back to $\mathrm{Fe}^{3+}$. The extent and ease of oxidation suggested that the iron was highly dispersed.

\section{DISCUSSION}

The observation that the highly dispersed sulfide cluster-derived ensembles were as or more active than a commercial $\mathrm{CoMo} / \gamma-\mathrm{Al}_{2} \mathrm{O}_{3}$ catalyst

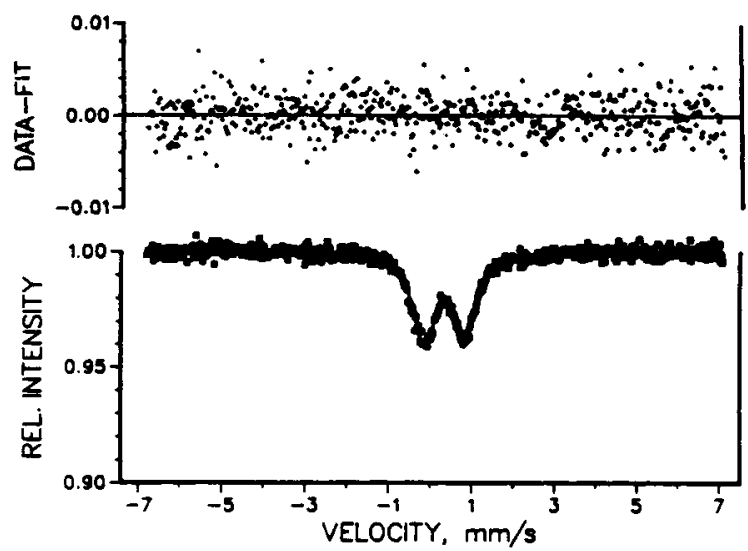

Figure 12 Mössbauer spectrum of MoFeS/A following exposure to air. The isomer shift suggested the presence of $\mathrm{Fe}^{3+}$. The spectral parameters are similar to those of the 'FeMoS' phase. $^{8}$ provides clear evidence that bulk phases are not required to produce the highly active sites characteristic of promoted Mo sulfide hydrotreatment catalysts. This implies that the models for the active site discussed earlier in this paper are somewhat overspecified.

There were three features that together appeared to govern the character of the active sites in the cluster-derived catalysts. First, the most active catalytic ensembles contained significant amounts of $\mathrm{Mo}^{0}$ and $\mathrm{Mo}^{\delta+}$, where $\delta<4$. This is consistent with those active-sites models which implicate reduced molybdenum, presumably in

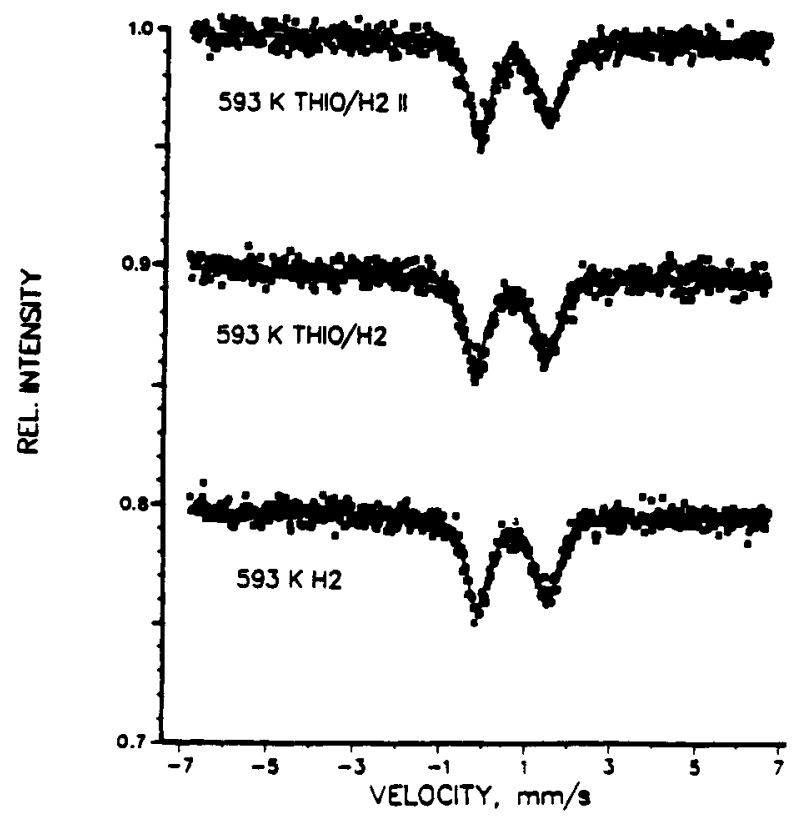

Figure 13 In situ Mössbauer spectra of MoFeS/A. The spectrum for the reduced catalyst possessed an $\mathrm{Fe}^{2+}$ doublet and a doublet that was assigned as $\mathrm{Fe}^{\xi+}$ where $\xi<2$. Exposure of the catalyst to the thiophene/hydrogen mixture did not signifcantly alter its spectrum. 
the form of $\mathrm{Mo}^{3+}$, as the active species. Gellman et al. ${ }^{40,41}$ also infer the importance of metallic Mo in HDS catalysis. The promoter element appeared to play both active and passive roles in determining the activity. Ensembles where molybdenum and cobalt were expected to be in intimate contact had the highest activities. We tentatively concluded that cobalt donated electron density to molybdenum or facilitated the reduction of molybdenum (active role), thereby enhancing the activity. According to Harris and Chianelli, ${ }^{42-44}$ elements that donate electrons and produce promotion include cobalt and nickel, and to a lesser extent iron. The simple presence of the promoter element appears important (passive role). For catalysts in which the molybdenum electronic structures were similar, those derived from bimetallic clusters containing molybdenum and cobalt or iron were more active than those derived from monometallic clusters. We propose that the catalytic site is centered on a molecularscale ensemble consisting of molybdenum, sulfur and the promoter element.

Catalytic sites in the cluster-derived catalysts appeared to be relatively accurate models of the sites in commercial hydrotreatment catalysts. In particular, catalytic ensembles derived from the MoCoS and MoFeS clusters modelled those present in the promoted catalysts, while ensembles drived from MoS modelled sites present in $\mathrm{MoS}_{2}$. Further characterization of these bimetallic ensembles could lead to a structural model of the so-called 'CoMoS'-type phase, given the similarities between the Mössbauer spectra of the $\mathrm{MoFeS} / \mathrm{A}$ and 'FeMoS' species.

\section{CONCLUSIONS}

In conclusion, highly dispersed sulfide clusterderived ensembles were active and selective catalysts for HDS and HDN. The most active catalysts were produced from the bimetallic clusters and contained significant amounts of reduced molybdenum; in fact, both HDS and HDN activities tracked with the extent of molybdenum reduction. We believe that the active sites in the bimetallic cluster-derived catalysts were centered on highly dispersed ensembles containing molybdenum, sulfur, and the promoter elements. These sites appeared to be similar to those in commercial hydrotreatment catalysts, as evidenced by the similarity between their activities and spectroscopic characters. Finally, discrete surface ensembles giving rise to Mössbauer spectra characteristic of the 'CoMoS' phase have been prepared. These materials may be useful for defining the structure of the 'CoMoS' site.

Acknowledgements The authors wish to thank Dr Amit Sachdev and Mr Brian Demczyk for assistance with the HRTEM and Professor M David Curtis, Dr Owen Curnow, Imad Bakkar and David Graf for the synthesis of the clusters. Financial support for this research was provided the National Science Foundation (ISI-8760441) and the Amoco Oil Company, and a fellowship was provided to JRB by the Chevron Oil Company.

\section{REFERENCES}

1. Lipsch, J M J G and Schuit, G C A J. Catal., 1969, 15: 179

2. Massoth, F E Adv. Catal., 1978, 27: 265.

3. Seshadri, K S, Massoth, F E and Petrakis, L J. Catal., 1970, 19: 95

4. Massoth, F E J. Catal., 1977, 50: 190

5. Delmon, B Prep. Am. Chem. Soc., Div. Pet. Chem., 1977, 22(2): 503

6. DeBeer, V H and Schuit, G C in: Preparation of Catalysts, Delmon, B, Jacobs, P and Poncelet, G (eds) Elsevier Publishers, New York, 1976, p 343

7. Topsøe, H, Clausen, B S, Candia, R, Wivel, C and Mørup, S J. Catal., 1981, 68: 433

8. Mørup, S, Clausen, B and Topsøe, H J. Phys., 1979, 40(C2): 88

9. Clausen, B S, Topsøe, H, Candia, R, Villadsen, J, Lengeler, B, Als-Nielsen, J and Christensen, F J. Phys. Chem., 1981, 85: 3868

10. Muetterties, E L, Rhodin, T N, Band, E, Brucker, C F and Pretzer, W R Chem. Rev., 1979, 79(2), 91

11. Yermakov, Y I J. Mol. Catal., 1983, 21: 35

12. Gates, B C In: Metal Clusters in Catalysis, Gates, B C, Guczi, L and Knözinger, H (eds), Elsevier Publishers, New York, 1986, p 415

13. Rakowski DuBois, M, VanDerveer, M C, Dubois, D L, Haltiwanger, R C and Miller, W K J. Am. Chem. Soc., 1980, 102: 7456

14. Curtis, M D and Williams, P D Inorg. Chem., 1983, 22: 2261

15. Williams, P D, Curtis, M D, Duffy, D N and Butler, W M Organometallics, 1983, 2: 165

16. Uchtman, V A and Dahl, L F J. Am. Chem. Soc., 1969, 91: 3756

17. Bogan, L E, Lesch, D A and Rauchfuss, T B J. Organomet. Chem., 1983, 250: 429

18. Williams, P D PhD Dissertation, Dept of Chemistry, University of Michigan, 1985

19. Reeves, A A MS thesis, Thayer School of Engineering, Dartmouth College, 1990 
20. Zmierczak, W, Muralidhar, G and Massoth, F EJ. Catal., 1982, 77: 434

21. Bodrero, T A and Bartholomew, C H J. Catal. 1983, 84: 145

22. Reddy, B M and Subrahmanyam, V S Appl. Catal., 1986, 27: 1

23. Shuxian, Z, Hall, W K, Ertl, G and Knözinger, $\mathbf{H}$ J. Catal., 1986, 100: 167

24. Segawa, K and Millman, W S J. Catal., 1986, 101: 430

25. Tauster, S J, Pecoraro, T A and Chianelli, R R J. Catal., 1980, 63: 515

26. Carvill, B T and Thompson, L T Appl. Catal., 1991, 75: 249

27. Curtis, M D, Penner-Hahn, J E, Schwank, J, Baralt, O, McCabe, D J, Thompson, L T and Waldo, G Polyhedron, 1988, 7: 2411

28. JCPDS International Centre for Diffraction Data, 'Powder Diffraction File', Swarthmore, PA, USA, 1991

29. Devenish, R W, Goodhew, P J, Heaton, B T, Jacobs, C and Mulley, S Sci. Prog., 1990, 74: 513

30. Pecoraro, T A and Chianelli, R R J. Catal, , 1981, 67: 430

31. Chianelli, R R, Pecoraro, T A, Halbert, T R, Pan, W H and Stiefel, E I J. Catal., 1984, 86: 226
32. Gates, B C, Katzer, J R and Schuit, G C A Chemistry of Catalytic Processes, McGraw-Hill, 1979, p 390

33. Ho, T C Catal. Rev.-Sci. Eng., 1988, 30(1): 117

34. Katzer, J R and Sivasubramanian, R Catal. Rev.-Sci. Eng., 1979, 20(2): 155

35. Kolousek, V, Palka, P, Hillerova, E and Zdrazil, M Coll. Czech. Chem. Comm., 1991, 56: 580

36. De Beer, V H J, Duchet, J C and Prins, R J. Catal., 1981, 72: 369

37. Duchet, J C, van Oers, E M, De Beer, V H J and Prins, $R$ J. Catal., 1983, 80: 386

38. Travis, J C An Introduction to Mössbauer Spectroscopy, May, L (ed), Plenum Press, London, 1971, p 75

39. Flinn, P A, Ruby, S L and Kehl, W L Science, 1964, 143: 1434

40. Gellman, A J, Neiman, D and Somorjai, G A J. Catal., 1987, 107: 92

41. Gellman, A J, Bussell, M E and Somorjai, G A J. Catal., 1987, 107: 103

42. Harris, S and Chianelli, R R J. Catal., 1986, 98: 17

43. Harris, S and Chianelli, R J. Catal., 1984, 86: 400)

44. Harris, S Polyhedron, 1986, 5: 151 